\title{
Working
}

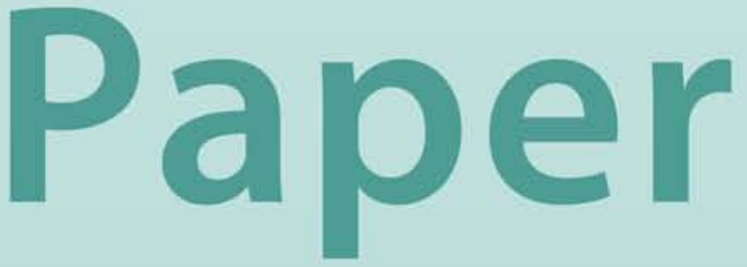




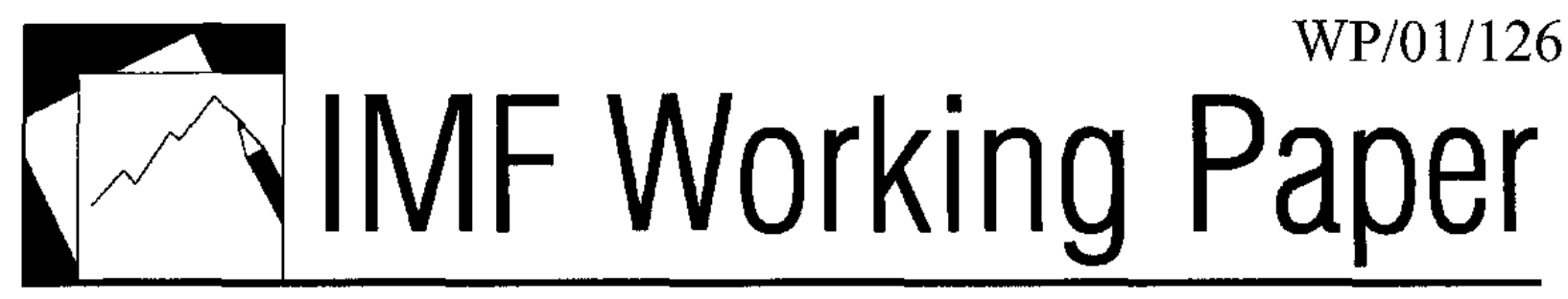

Subsidy Reforms and Poverty Alleviation

\author{
Parkash Chander
}




\title{
IMF Working Paper
}

Fiscal Affairs Department

\section{Subsidy Reforms and Poverty Alleviation}

\author{
Prepared by Parkash Chander' \\ Authorized for distribution by Sanjeev Gupta
}

September 2001

\begin{abstract}
The views expressed in this Working Paper are those of the author(s) and do not necessarily represent those of the IMF or IMF policy. Working Papcrs describe research in progress by the author(s) and are published to elicit comments and to further debate.
\end{abstract}

This paper presents a general framework for characterizing the optimal pattern of subsidies for poverty alleviation under budgetary constraints and suggests possible reforms for the existing pattern of subsidies. The government may subsidize or tax goods in order to meet its objectives. The paper introduces the concept of a consumer equilibrium and shows that there are cases of equilibria in which reforms can generate not only fiscal savings but also Pareto improve the welfare of both poor and wealthy consumers.

JEL Classification Numbers: D11, H2, H3, H42, H5, I13

Keywords: poverty, subsidy, reforms, quality, deadweight loss

Author's E-Mail Address:chander@isid.ac.in

\footnotetext{
${ }^{1}$ Indian Statistical Institute, Delhi; e-mail address: chander@isid.ac.in. The author completed this paper as a visiting scholar to the IMF. The author wishes to thank Sanjeev Gupta and the Fiscal Affairs Department of the International Monetary Fund for the opportunity to complete this paper. In particular, he would like to thank Sanjeev Gupta, Luc Leruth, Robert Gillingham, and Benedict Clements for suggestions and comments.
} 


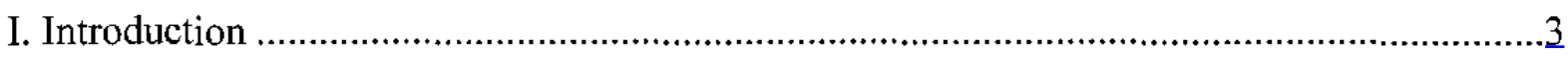

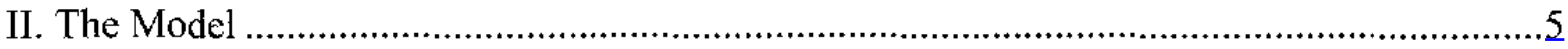

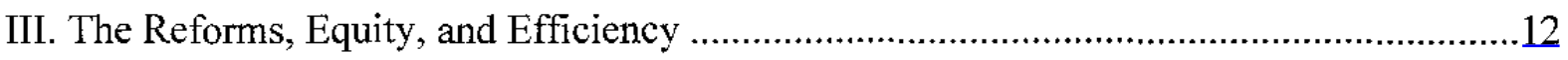

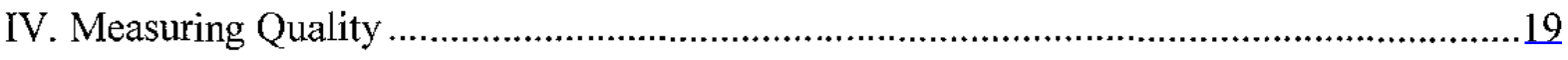

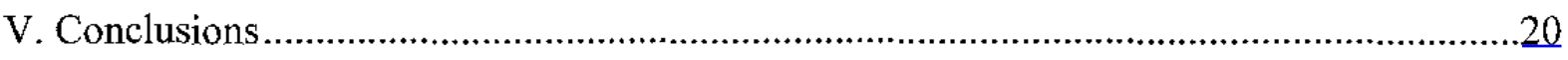

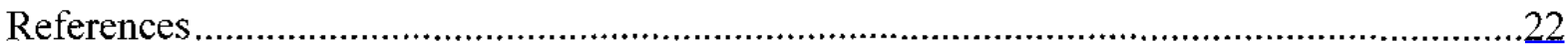




\section{INTRODUCTION}

The question of subsidies for private goods and services, such as energy, food, and health care, is at the forefront of most discussions of macroeconomic adjustment in many developing countries. On the one hand, it is argued that these subsidies redistribute income from the wealthy to the poor and are necessary for meeting the government's poverty alleviation objective. ${ }^{2}$ On the other hand, it is claimed that the pattern of these subsidies, as it stands, is not appropriate for achieving the poverty alleviation objective cost-effectively, as there are substantial "leakages" to the nonpoor. Reforms of the existing pattern of subsidies so as to minimize the leakages and realize the government's objective in a cost-effective manner should be thus undertaken. ${ }^{3}$

The purpose of this paper is to present a general framework in which these issues can be analyzed. In particular, what is the optimal pattern of subsidies for poverty alleviation under budgetary constraints? ${ }^{4}$ How can reforms of the existing pattern of subsidies achieve fiscal savings without compromising the poverty alleviation objectives? Will such reforms reduce the deadweight loss or increase it?

An important consideration underlying our proposed framework is that it is not possible to identify the poor in any cost-effective manner, if at all. ${ }^{5}$ Therefore, only those subsidy schemes that are universal, in the sense that everyone is eligible, can be considered. Such schemes, however, need not be de facto universal. Subsidizing only those goods that the poor prefer can limit through self-selection or self-targeting the consumption of subsidized goods to the poor alone. ${ }^{6}$ As shown in Chander and Leruth (1989) and Besley and Coate (1991), such self-targeting can be achieved via differences in product quality, if quality is a normal good. For example, some commuters in Jakarta do not use subsidized public bus service and instead pay more for a higher-quality private bus service (Ahmad and Leruth, 2000).

\footnotetext{
${ }^{2}$ History shows that cuts in these subsidies can indeed lead to real income losses to the poor and even political unrest in some cases. For this reason, IMF-supported programs in many countries aim at achieving the fiscal benefits of subsidy reforms with minimal social distuption.

${ }^{3}$ A review of the experiences of a wide range of countries, along with a guide for policy makers regarding subsidy reforms, can be found in Gupta and others (2000).

${ }^{4}$ By a subsidy we mean, as in Schwartz and Clements (1999), any government assistance that allows consumers to purchase goods and services below the perfectly competitive market prices. Thus, cash transfers are ruled out.

s Such identification requires the means testing of a large number of households. Moreover, the households may attempt to understate their incomes, and the information gatherers may not make sufficient effort to obtain the information accurately and may even be prone to corruption and manipulation.

${ }^{6}$ In an interesting case study, Tuck and Lindert (1996) and Alderman and Lindert (1998) show that switching to self-targeted subsidies can indeed reduce the fiscal cost of food subsidies and improve their incidence.
} 
Assuming that quality is a normal good, the commuters who do not use the public bus service will be those with higher incomes. Thus, the bus subsidy will be availed of exclusively by those with low incomes.

From a policy point of view, it is a question not only of what should be the level of subsidies for the goods demanded by the poor, but also of what should be the prices of the high-quality substitute goods preferred by the nonpoor. Relatively high prices of the latter can induce the nonpoor to switch to the subsidized goods meant for the poor and thus adversely affect the fiscal balance. The subsidy reforms should therefore include the prices of both high- and low-quality goods. To continue the example, if private bus service is "too expensive," even the higher-income commuters may switch to the subsidized public bus service, leading to a higher government expenditure for the bus subsidy.

The framework for the study consists of a discrete choice model in which individuals can make indivisible and mutually exclusive purchases from among $n$ substitute goods, ${ }^{7}$ which differ in quality. It is assumed that producers behave competitively and each consumer's utility function is such that his/her willingness to pay for quality increases with income. The government may subsidize or tax goods in order to meet its objectives. The study introduces the concept of a consumer equilibrium and shows that whatever the subsidies and taxes may be, higher-income consumers will never buy goods of lower quality, though unlike in a competitive equilibrium, some goods of intermediate quality may not be demanded by the consumers at all. It is then shown that there are cases of equilibria in which reforms can generate not only fiscal savings but also Pareto improve the welfare of both the poor and wealthy consumers.

This paper is organized as follows. Section 2 sets up the model and introduces the concept of a consumer equilibrium. Section 3 characterizes the optimal pattern of subsidies and taxes for poverty alleviation under budgetary constraints and identifies the cases in which reforms can generate fiscal savings as well as lead to Pareto improvements in the welfare of consumers. This section also identifies those cases in which reforms may reduce the deadweight loss. Section 4 shows as a by-product of this study's framework how the quality of various goods - a hedonic attribute-can be estimated. Section 5 draws conclusions and reviews the policy implications of the analysis.

\footnotetext{
${ }^{7}$ We make this simplifying assumption in order to obtain sharper results. However, as noted by Besley and Coate (1991), there are many interesting cases in which this assumption is satisfied. For example, it may be neither desirable nor possible for an individual to receive health care simultaneously from two different sources, which might differ in quality.
} 


\section{THE ModeL}

Consider a population of consumers identical in tastes, but differing in income. Assume that income is distributed over an interval $[0, \bar{y}], \bar{y}>0$, according to a density function $f(y)$. The following analysis focuses especially on two extreme cases of the density function, namely, discrete and uniform with support over an interval $[\underline{y}, \bar{y}], \underline{y}>0$.

Assume that consumers can make indivisible and mutually exclusive purchases from among $n$ substitute goods; that is, each consumer can purchase none or just one unit of one of the goods. The goods differ in quality and let us denote the utility derived by consuming one unit of a good with quality $q$, and $y$ units of income or numeraire as $u(y, q)$. Let us adopt the convention that $q=0$ if an individual consumes none of the goods. Let the utility function take the specific form: ${ }^{8}$

$$
u(y, q)=y(1+q)
$$

Clearly the marginal rate of substitution between quality and income $\left(=u_{q} / u_{y}\right)$ is decreasing in $q$ and increasing in $y$; that is, the willingness to pay for quality is increasing with income. Let the $n$ substitute goods be labeled in an increasing order of quality $0<q_{1}<q_{2} \ldots<q_{n}$.

Assume that the economy uses a technology that transforms $p q$ units of the numeraire into one unit of the indivisible good with quality $q$. The cost of quality at the margin is thus $p{ }^{9}$

Consider first the competitive equilibrium of this economy. If producers behave competitively, the market price of a good with quality $q_{i}$ is $p_{i}=p q_{i}$. The utility of an individual with income $y$ who purchases one unit of a good with quality $q_{i}$ is then $\left(y-p_{i}\right)\left(1+q_{i}\right)$. Each consumer will choose the good that maximizes his/her utility. Of course, a consumer may decide not to consume any good, in which case $p_{i}=q_{i}=0$. It is clear from the first fundamental theorem of welfare economics that competitive equilibria will lead to Pareto-efficient allocations.

Figure 1 illustrates the choice problem facing a consumer in the case of three goods,

\footnotetext{
${ }^{8}$ The reason for this specification of the utility function is that it simplifies the calculus of a consumer's surplus.

${ }^{9}$ As will be clear later, the following results do not depend on this assumption.
} 
i.e., $0<q_{1}<q_{2}<q_{3}$. Income is plotted on the horizontal axis and the gain in a consumer's utility from a good with quality $q_{i}$, i.e., $u\left(y-p_{t}, q_{i}\right)-u(y, 0)=y q_{i}-p_{i}\left(1+q_{i}\right)$, is plotted on the vertical axis. The consumer's gain in utility from a good with quality $q_{i}$ is an increasing linear function of $y$ whose slope and intercept are $q_{i}$ and $p_{i}\left(1+q_{i}\right)=p q_{i}\left(1+q_{i}\right)$, respectively. The upper envelope of the three lines corresponding to the three goods, as indicated by the thick curve, represents the actual gain in consumer's utility from the set of three goods, that is, $v(p, y)-y$, where $v(p, y)$ is the indirect utility function. The corner points of the envelope are given by, $y_{1}=p\left(1+q_{1}\right), y_{2}=p\left(1+q_{1}+q_{2}\right)$, and $y_{3}=p\left(1+q_{2}+q_{3}\right)$.

Since $0<q_{1}<q_{2}<q_{3}, 0<y_{1}<y_{2}<y_{3}$. Clearly, the consumers with incomes below $y_{1}$ will not demand any good; consumers with incomes between $y_{1}$ and $y_{2}$ will demand good 1 ; consumers with incomes between $y_{2}$ and $y_{3}$ good 2 ; and consumers with incomes above $y_{3}$, good 3 . Thus, in a competitive equilibrium, the consumers will be divided into separate income groups with the lower-income groups buying lower-quality goods.

The convexity of the upper envelope of the three lines in Figure 1 implies that the gain in utility from the set of three goods increases more than proportionately with income. Now consider a uniform price subsidy $s>0$. This means that the market price of one unit of goods with quality $q_{i}$ is now $(p-s) q_{i}$. Such a subsidy benefits all individuals including those with low incomes, but, as is easily seen, it is regressive in the sense that it confers relatively higher benefits on high-income individuals vis-à-vis low-income ones. ${ }^{10}$

Since government's objective is to redistribute welfare in favor of low-income individuals, we need to consider nonuniform subsidies/taxes. Let $s_{i}>0(<0)$ be the price subsidy (tax) for a good with quality $q_{i}$ and let $p_{i}=\left(p-s_{i}\right) q_{i}$ denote its after-subsidy (tax) price.

Unlike uniform subsidies, nonuniform subsidies/taxes open up the possibility that $q_{i}<q_{j}$ but $p_{i}>p_{j}$. In such a case, consumers will simply not demand the good with quality $q_{i}$. Clearly, $q_{i}<q_{j}$ and $p_{i}>p_{j}$ imply $\left(y-p_{i}\right)\left(1+q_{i}\right)<\left(y-p_{j}\right)\left(1+q_{j}\right)$ for all $y \geq p_{i}$. (For $y-p_{i}<0$, the consumer will not demand good $i$ in any case.) However, as will be seen later, this is not the only case in which the consumers may not demand a good. It depends on the relative price-quality tradeoff a good offers.

\footnotetext{
${ }^{10}$ Suppose simply that quality can take any value. Then a utility-maximizing consumer will demand a good with quality $q=(y-(p-s)) / 4(p-s)$ and his/her utility gain will be $(y-(p-s))^{2} / 4(p-s)$. The difference[ $\left.(y-(p-s))^{2} / 4(p-s)\right]-$ $\left[(y-p)^{2} / 4 p\right]$ clearly increases and is convex in $y$ for $s>0$. Obviously, the same must be true even if quality can take only some discrete values.
} 
As before, however, higher-income individuals will not demand lower-quality goods, whatever may be the after-subsidy ( $\operatorname{tax}$ ) prices. Clearly, if a consumer with income $y$ prefers $q_{i}$ to $q_{j}$. (i.e., $\left.y q_{i}-p_{i}\left(1+q_{i}\right)>y q_{j}-p_{j}\left(1+q_{j}\right)\right)$ and $q_{i}>q_{j}$, then all consumers with income $z>y$ will also prefer $q_{i}$ to $q_{j}\left(i . e ., z q_{i}-p_{i}\left(1+q_{i}\right)>z q_{j}-p_{j}\left(1+q_{j}\right)\right)$ whatever may be the prices $p_{l}, \ldots, p_{n}$. 
$-8-$

Figure 1

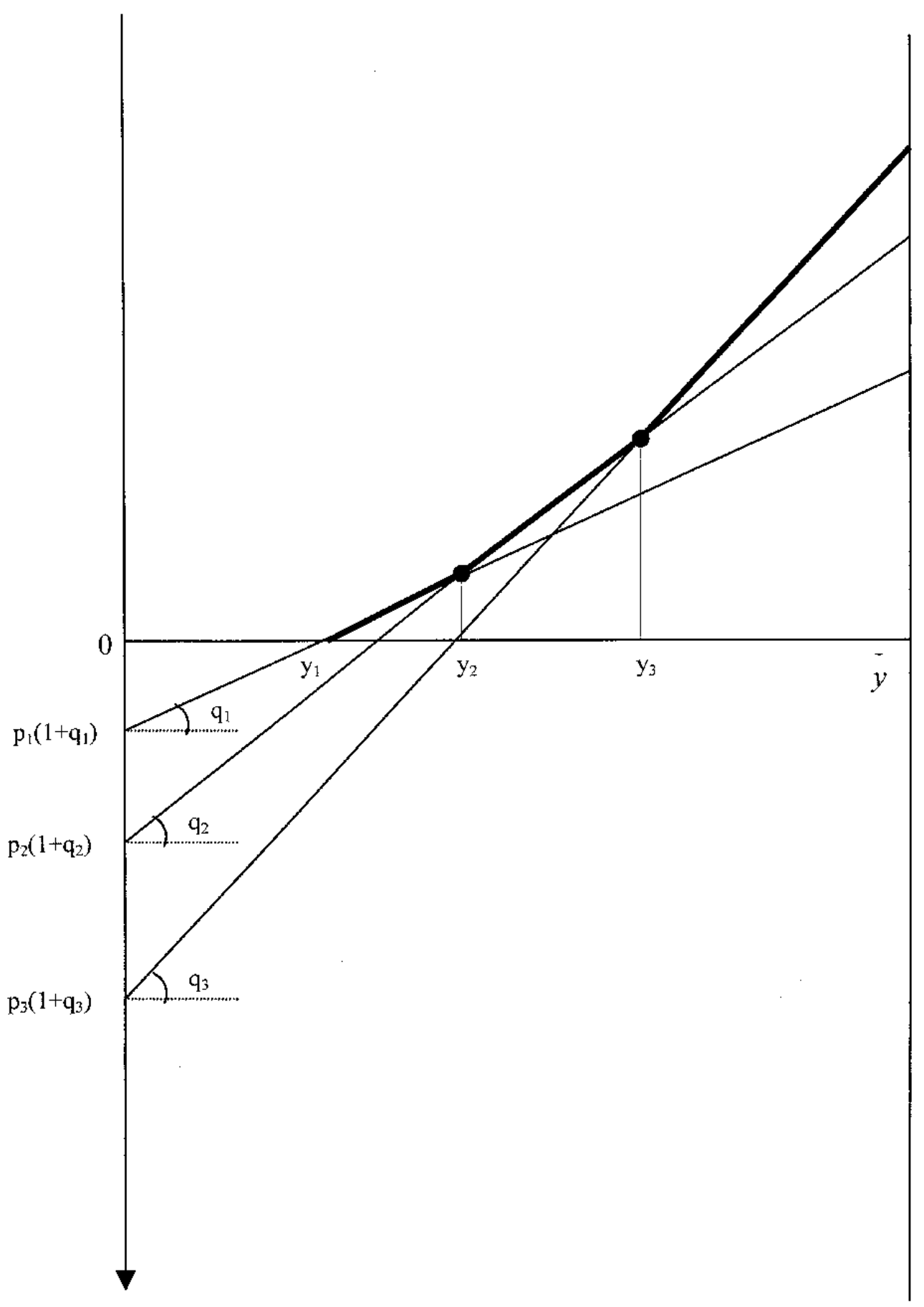


We are now well prepared to introduce the concept of a consumer equilibrium.

Let $p_{I}, p_{2}, \ldots p_{n}$ be some after-subsidy (tax) prices of the $n$ goods and let $N=\{1,2, \ldots, n\}$. Then $p_{l}, p_{2}, \ldots p_{n}$ induce a consumer equilibrium if there exist some $m(0 \leq m \leq n)$ goods of qualities $q_{(1)}, q_{(2)} \ldots, q_{(m)}$ where $(i) \in N$ for $i=1,2, \ldots, m$, and income levels $y_{l}, y_{2}, \ldots, y_{m}$ such that $0 \leq y_{1}<y_{2} \ldots<y_{m} \leq \bar{y}, y_{1} q_{(1)}-p_{(1)}\left(1+q_{(1)}\right)=0$ and $y q_{i}-p_{i}\left(1+q_{i}\right) \leq 0$ for all $i \in N$ and $y \in\left[0, y_{1}\right]$; for each $j=1,2, \ldots, m-1, y q_{(j)}-p_{(j)}\left(1+q_{j}\right) \geq y q_{i}-p_{i}\left(1+q_{i}\right)$ for all $i \in N$ and $y \in\left\lfloor y_{j}, y_{j+1}\right\rfloor$; and $y q_{(m)}-p_{(m)}\left(1+q_{(m)}\right) \geq y q_{i}-p_{i}\left(1+q_{i}\right)$ for all $i \in N$ and $y \in\left\lfloor y_{m}, \bar{y}\right\rfloor$.

In a consumer equilibrium, consumers with incomes between $\left[0, y_{1}\right]$ will not demand any good, those with incomes in $\left\lfloor y_{j}, y_{j+1}\right\rfloor, j=1,2, \ldots, m-1$, will demand $\operatorname{good}(j)$ and those with incomes in $\left\lfloor y_{m}, \bar{y}\right\rfloor \operatorname{good}(m)$.

In view of the observations earlier, in a consumer equilibrium, the relationship must be $q_{(1)}<q_{(2)}<\ldots<q_{(m)}$. However, unlike in a competitive equilibrium, the after-subsidy (tax) prices may be such that some goods of intermediate quality are eliminated in the sense that they are not demanded by any consumer. Figure 2 illustrates one such case. ${ }^{11}$

Theorem: Let $p_{1}, p_{2}, \ldots, p_{\mathrm{n}}$ be some after-subsidy (tax) prices of the $n$ substitute goods. Then $p_{1}, p_{2}, \ldots, p_{n}$ induce a consumer equilibrium, which is unique.

Proof: A constructive proof of this theorem is as follows. Let $Q$ denote the set $\left\{q_{l}, q_{2}, \ldots\right.$, $\left.q_{n}\right\}$. Define

$$
q_{(I)}=\max \left\{q_{j} \in Q: \frac{p_{j}\left(1+q_{j}\right)}{q_{j}}=\min _{i} \frac{p_{i}\left(1+q_{i}\right)}{q_{i}}\right\}
$$

and

$$
y_{1}=\frac{p_{(1)}\left(1+q_{(1)}\right)}{q_{(1)}} .
$$

\footnotetext{
"In this case the utility gains from goods of qualities $q_{l}$ and $q_{2}$ are equalized at an income level, which is higher than the one that equalizes the utility gains from goods of qualities $q_{l}$ and $q_{3}$. This possibility is ruled out in the case of competitive equilibria, since as noted earlier $y_{1}<y_{2}<y_{3}$.
} 
$-10-$

Figure 2

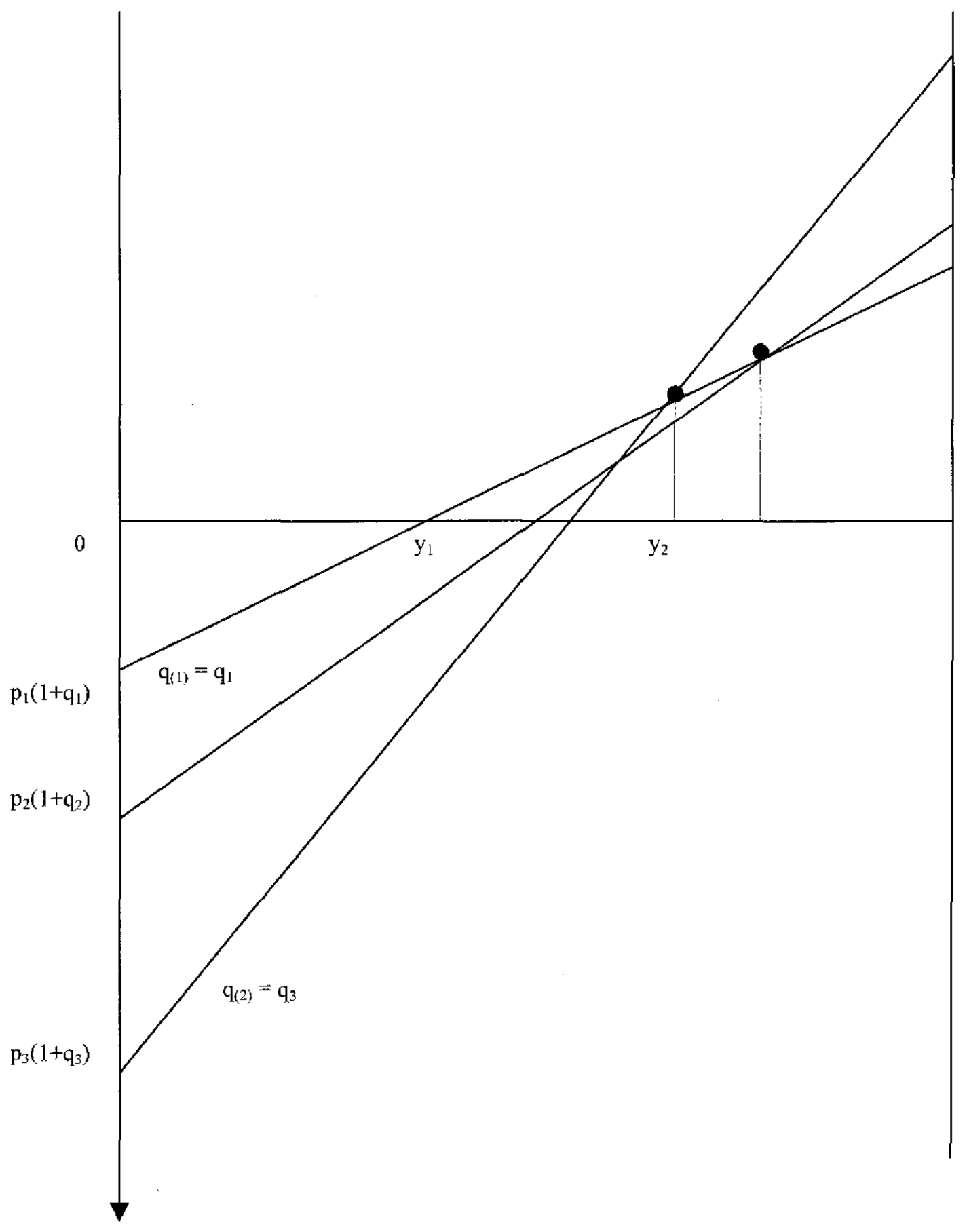


Next, define $q_{(i)}, 1<(i) \leq n$, from $q_{(i-1)}$ as follows:

$q_{(i)}=\max \left\{q_{j} \in Q: \frac{p_{j}\left(1+q_{j}\right)-p_{(i-1)}\left(1+q_{(i-1)}\right)}{q_{j}-q_{(i-1)}}=\min _{k>(i-1)} \frac{p_{k}\left(1+q_{k}\right)-p_{(i-1)}\left(1+q_{(i-1)}\right)}{q_{k}-q_{(i-1)}}\right\}$

and

$$
y_{i}=\frac{p_{(i)}\left(1+q_{(i)}\right)-p_{(i-1)}\left(1+q_{(i-1)}\right)}{q_{(i)}-q_{(i-1)}} .
$$

Finally, define

$$
m=\max \left\{i \in N: y_{i} \leq \bar{y}\right\},
$$

where $y_{i}{ }^{\prime} s$ are as defined in (2) and (3).

Obviously, there exists a solution to equation (1). $m=1$ if either $q_{(1)}=q_{n}$ or $y_{1} \geq \bar{y}$. We therefore consider the case in which $q_{(1)} \neq q_{n}$ and $y_{1}<\bar{y}$. We can show that if $q_{(1)} \neq q_{n}$, then equation (3) has a solution for $i=2$. This is as follows: since $q_{(1)} \neq q_{n}$, there exists a $j$ such that $q_{j}>q_{(1)}$ and $p_{j}\left(1+q_{j}\right) / q_{j}>p_{(1)}\left(1+q_{(1)}\right) / q_{(1)}$, which implies that $p_{j}\left(1+q_{j}\right)>p_{(1)}\left(1+q_{(1)}\right)$ for any $j>(1)$. This proves that equation (3) must have a solution for $i=2$. Similarly, given $q_{(2)}$, equation (3) must have a solution for $i=3$, and so on.

Next, we can show that $y_{1}<y_{2}<\ldots<y_{m}$. Suppose, contrary to the assertion, that $y_{1}>y_{2}$. Since $y_{2}=\left\lfloor p_{(2)}\left(1+q_{(2)}\right)-p_{(1)}\left(1+q_{(1)}\right\rfloor /\left(q_{(2)}-q_{(1)}\right)\right.$, that is $y_{2} q_{(2)}-p_{(2)}\left(1+q_{(2)}\right)=y_{2} q_{(1)}-p_{(1)}\left(1+q_{(1)}\right)$ and $q_{(2)}>q_{(1)}, y_{1}>y_{2}$ implies $y_{1} q_{(2)}-p_{(2)}\left(1+q_{(2)}\right)>y_{1} q_{(1)}-p_{(1)}\left(1+q_{(1)}\right)$. But this contradicts that $y_{1}=\min _{i}\left\{p_{i}\left(1+q_{i}\right) / q_{i}\right\}$. This proves that $y_{2}>y_{1}$. Similarly $y_{2}>y_{3}$ implies

$y_{2} q_{(3)}-p_{(3)}\left(1+q_{(3)}\right)>y_{2} q_{(2)}-p_{(2)}\left(1+q_{(2)}\right)=y_{2} q_{(1)}-p_{(1)}\left(1+q_{(1)}\right)$, which is a contradiction to the definition of $y_{2}$. This proves that we must have $y_{1}<y_{2}<\ldots<y_{m}$. Therefore, $0 \leq y_{1}<y_{2}<\ldots<y_{m} \leq \vec{y}$ in view of (4) and $q_{(1)}<q_{(2)}<\ldots<q_{(m)}$ as noted earlier.

This proves that $p_{1}, p_{2}, \ldots, p_{n}$ induces a consumer equilibrium. The proof of uniqueness is 
straightforward. Suppose the equilibrium is not unique. Let $0 \leq \hat{y}_{1}<\hat{y}_{2}<\ldots<\hat{y}_{k} \leq \bar{y}$ and $\hat{q}_{(1)}<\hat{q}_{(2)}<\ldots<\hat{q}_{(k)}$ be the corresponding partition of $[0, \bar{y}]$ and quality levels. It is easily seen that we must have $\hat{y}_{i}=y_{i}$ and $\hat{q}_{(i)}=q_{(i)}$ for each $i$ and $k=m$ as in equations (2), (3), and (4).

This completes the proof.

\section{REFORMS, EQUITY, AND EFFICIENCY}

There is a complete separation between the demand and supply sides of our model and thus the consumer equilibria are independent of how income is distributed, i.e., the density function $f(y)$. This is a straightforward consequence of our assumption that each good with quality $q_{i}$ can be produced at a constant marginal cost $p q_{i}$. The fiscal implications of a consumer equilibrium, however, depend on the density function $f(y)$, since besides depending on the rates at which the goods are subsidized or taxed, the fiscal balance also depends upon how many consumers buy each of the goods.

We can now characterize the optimal pattern of subsidies/taxes for poverty alleviation under budgetary constraints. In order to keep matters simple, we will assume that there are only two goods with qualities $q_{1}$ and $q_{2}$ with $q_{1}<q_{2}$. In view of our characterization of a consumer equilibrium, we assume that the objective of the government is to subsidize the low-quality good to the maximum extent possible without exceeding a prespecified fiscal deficit level, say $F$, but by possibly imposing a tax on the high-quality good. ${ }^{12}$ That is, ${ }^{13}$

$\operatorname{minimize}_{s_{1}}\left(p-s_{1}\right) q_{1}$

subject to

$$
s_{2} q_{2} \int_{y_{2}}^{\bar{y}} f(y) d y-s_{1} q_{1} \int_{y_{1}}^{y_{2}} f(y) d y+F=0
$$

\footnotetext{
${ }^{12}$ For example kerosene, which is used as a cooking fuel by the poor, may be subsidized, while its high-quality substitute natural gas may be taxed. Gupta and Mahler (1995) have studied the distributional implications of subsidies and taxes on petroleum products and surveyed different underlying considerations.

In some cases it may be optimal to subsidize both the goods, though not to the same extent. However, we will ignore this possibility, as the analysis of this case is similar.

${ }^{13}$ For obvious reasons, the formulation ignores the trivial case in which the consumers demand only the lowquality good, i.e., when $y_{2} \geq \bar{y}$.
} 
where $s_{1}, s_{2} \geq 0$ are the subsidy and tax on goods with qualities $q_{1}$ and $q_{2}$, respectively, and in view of (2) and (3) and the fact that $p_{i}=\left(p-s_{i}\right) q_{i}, i=1,2$,

and

$$
y_{1}=\left(p-s_{1}\right)\left(1+q_{1}\right)
$$

$$
y_{2}=\frac{\left(p+s_{2}\right) q_{2}\left(1+q_{2}\right)-\left(p-s_{1}\right) q_{1}\left(1+q_{1}\right)}{q_{2}-q_{1}} .
$$

Let $\left(s_{1}^{*}, s_{2}^{*}, y^{*}, y^{*}{ }_{2}\right)$ be the optimal solution to this problem for a given $F$. The individuals with income in the interval $\left[y_{1}^{*}, y_{2}^{*}\right]$ will demand the low-quality good and thereby avail themselves of the subsidy. Clearly, $y^{*}$ and $y^{*}{ }_{2}$ are both functions of $F$ as are $s^{*}$ and $s^{*}{ }_{2}$. The government may then adjust $F$ depending on the extent to which the interval $\left[y^{*}{ }_{1}, y^{*}{ }_{2}\right]$ covers or does not cover its targeted income group. As seen from Figure 3, a higher $F$ will lead to a higher $s^{*}$, and a lower $s_{2}^{*}$ and therefore to a lower $y_{1}^{*}$ and a higher $y_{2}{ }_{2}$.

In order to simplify matters further, we will now consider two specific cases of the density function $f(y)$. In the first case, we will assume that incomes are uniformly distributed on some support so that $f(y)=1$ on $\lfloor y, \bar{y}\rfloor, \underline{y}>0$, and zero otherwise. In the second case, we will assume that incomes can take at most three distinct values, $y_{L}, y_{M}$, and $y_{H}$ with $f\left(y_{L}\right)=\alpha, f\left(y_{M}\right)=\beta$, and

$f\left(y_{M}\right)=\gamma$, where $\alpha+\beta+\gamma=1$.

In the first case, the fiscal constraint (5) reduces to

$$
s_{2} q_{2}\left(\bar{y}-y_{2}\right)-s_{1} q_{1}\left(y_{2}-\max \left\{y_{1}, \underline{y}\right\}\right)+F=0 \text {. }
$$

In order to avoid discussing many cases, we will assume, henceforth, that $\max \left\{y_{1}, \underline{y}\right\}=\underline{y}$, i.e., $y>p\left(1+q_{1}\right)$ and take $F=0$. Then by substituting from equation (7) and rearranging, we can rewrite the above equations as

$$
s_{2} q_{2}\left(\bar{y}-y_{2}^{c}\right)-s_{1} q_{1}\left(y_{2}^{c}-\underline{y}\right)-\left(s_{1} q_{1}+s_{2} q_{2}\right)\left(\frac{s_{1} q_{1}\left(1+q_{1}\right)+s_{2} q_{2}\left(1+q_{2}\right)}{q_{2}-q_{1}}\right)=0
$$

where $0 \leq y^{c}{ }_{1}<y_{2}^{c}<\bar{y}$ is the partition of $[0, \bar{y}]$ corresponding to the competitive equilibrium. 
Figure 3

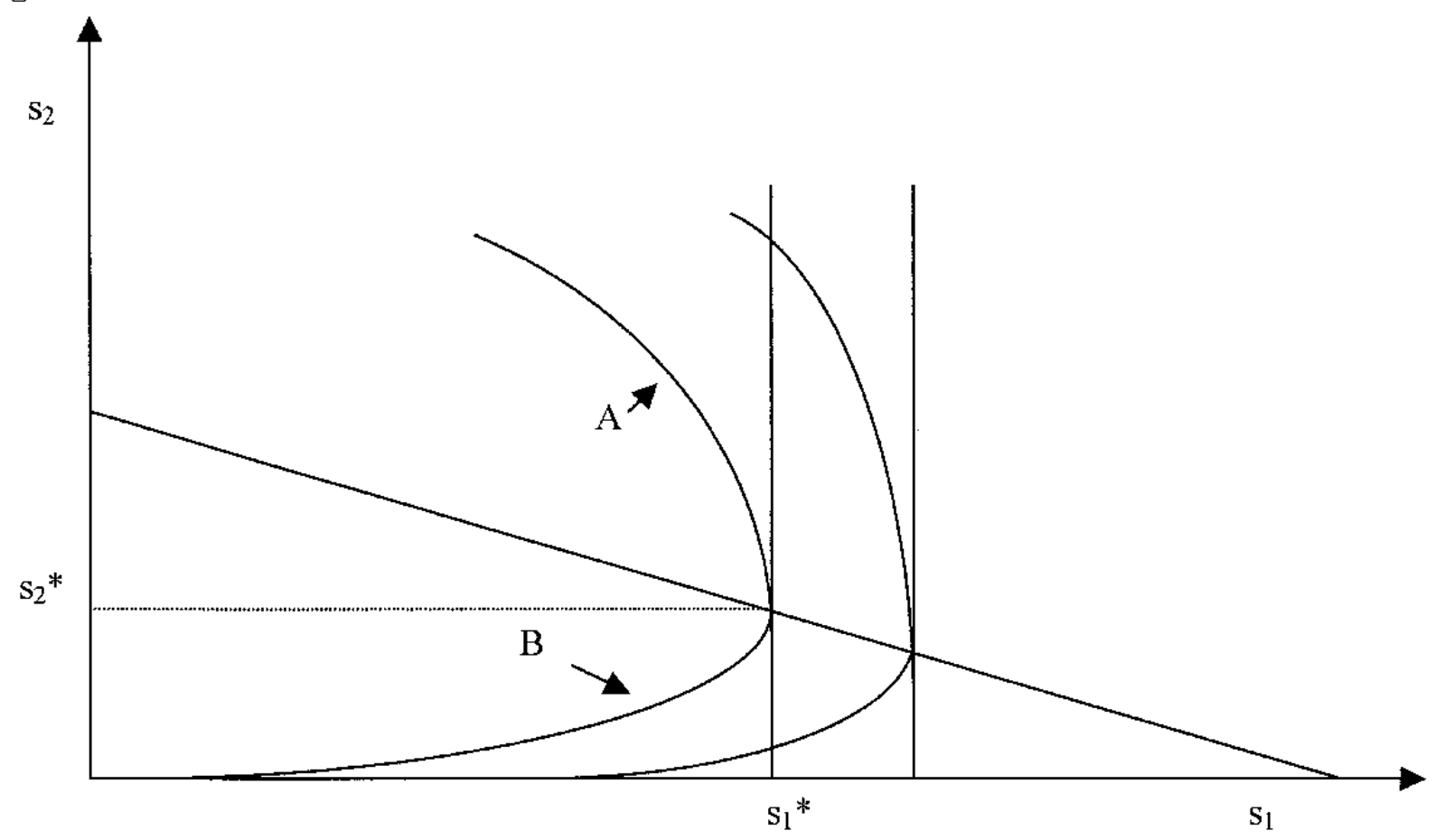


Since the objective is to minimize $\left(p-s_{1}\right) q_{1}$, subject to (8), we must have $d s_{1} / d s_{2}=0$, that is,

$$
\left(\bar{y}-y_{2}{ }^{c}\right)-\left(\frac{s_{1} q_{1}\left(1+q_{1}\right)+s_{2} q_{2}\left(1+q_{2}\right)}{q_{2}-q_{1}}\right)-\left(s_{1} q_{1}+s_{2} q_{2}\right)\left(\frac{1+q_{2}}{q_{2}-q_{1}}\right)=0 \text {, }
$$

which is linear in $s_{1}$ and $s_{2}$.

The optimal solution as determined by (8) and (9) is illustrated in Figures 3 and 4 . The outer curve in Figure 3 corresponds to the case $F>0$.

Two types of nonoptimal consumer equilibria are displayed as points $\mathrm{A}$ and $\mathrm{B}$ in Figure 3 and as $y_{2}{ }^{A}$ and $y_{2}{ }^{B}$ in Figure 4. At A, we have $d s_{1} / d s_{2}<0$ while at B, $d s_{1} / d s_{2}>0$. The subsidy reforms in the case of $A$ require tax $\left(s_{2}\right)$ to be decreased and subsidy $\left(s_{1}\right)$ to be increased. As seen from Figure 4, this would raise the welfare of all consumers. In the case of $B$, both tax and subsidy must be increased, which as seen from Figure 4 would raise the welfare of low-income individuals, but reduce that of high-income individuals.

In the case of $\mathrm{A}$, attempts at reducing the fiscal deficit by raising the tax on high-quality goods will reduce the tax revenue and, therefore, the subsidy rate and the welfare of all consumers, but enlarge coverage. This corresponds to the case shown as $\widetilde{y}_{2}$ in Figure 4.

In order to emphasize that our conclusions do not depend on the particular density function assumed, we now consider the case of another density function, namely, discrete. First, as is easily seen, there can be only two types of optimal consumer equilibria. In the first type, only the individuals with high income $y_{H}$ demand the high-quality good and in the second type, individuals with both income $y_{M}$ and $y_{H}$ demand the high-quality good. Straightforward arguments show that the second type of equilibrium is likely to prevail if the middle income group (i.e., " $\beta$ ") is sufficiently large. This type of optimal consumer equilibrium corresponds to the point vertically above $y_{M}$ in Figure 5. If the existing consumer equilibrium corresponds to the point vertically above $y_{2}$ then the subsidy reforms require, as in the case of the uniform density function, a reduction in the tax on the high-quality good and a rise in the subsidy on the low-quality good.

While the proposed subsidy reforms reduce poverty, do they also minimize the deadweight loss? The answer is that it depends. To see this, we define $m\left(s_{1}, s_{2}\right)$ as

$$
v\left(p, y+m\left(s_{1}, s_{2}\right)\right)=\max _{i}\left(y-\left(p-s_{i}\right) q_{i}\right)\left(1+q_{i}\right),
$$

where $s_{i}$ is the subsidy on the good with quality $q_{i}$ and $v$ as defined earlier is the indirect utility 
function. The function $m\left(s_{1}, s_{2}\right)$ represents the amount of money that an individual with income $y$ will have to be given to make him as well off as the subsidies $s_{1}, s_{2}$.

In the case of a consumer who chooses a good with quality $q_{1}$, the deadweight loss is equal to $s_{1} q_{1}-m\left(s_{1}, s_{2}\right)$. From a comparison of the competitive equilibrium and the consumer equilibrium corresponding to $\left(p-s_{1}\right) q_{1},\left(p+s_{2}\right) q_{2}$ as shown in Figure 5, it is clear that consumers with income in the interval $\left(y_{2}{ }^{c}-s_{1} q_{1}, y_{2}\right)$ only will switch from the good with quality $q_{1}$ to the good with quality $q_{2}$ when offered a cash transfer equal to $s_{1} q_{1}$ in lieu of the subsidies $s_{1}, s_{2}$.

Therefore, the function $m\left(s_{1}, s_{2}\right)$ must satisfy for each $y \in\left(y_{2}^{c}-s_{1} q_{1}, y_{2}\right)$,

$$
\left(y+m\left(s_{1}, s_{2}\right)-p q_{2}\right)\left(1+q_{2}\right)=\left(y-p q_{1}+s_{1} q_{1}\right)\left(1+q_{1}\right) .
$$

Hence, after substituting $y_{2}^{c}=p\left(1+q_{1}+q_{2}\right)$ as shown earlier,

$$
s_{1} q_{1}-m\left(s_{1}, s_{2}\right)=\left(s_{1} q_{1}+y-y_{2}{ }^{c}\right)\left(\frac{q_{2}-q_{1}}{1+q_{2}}\right) \text { if } y \in\left(y_{2}^{c}-s_{1} q_{1}, y_{2}\right) \text { and equal to zero otherwise. }
$$

Similarly,

$$
s^{*}{ }_{1} q_{1}-m\left(s_{1}, s_{2}\right)=\left(s^{*}{ }_{1} q_{1}+y-y_{2}{ }^{c}\right)\left(\frac{q_{2}-q_{1}}{1+q_{2}}\right) \text { if } y \in\left(y_{2}{ }^{c}-s^{*}{ }_{1} q_{1}, y^{*}{ }_{2}\right)
$$

and equal to zero otherwise.

Notice that, as shown in Figure $5, y^{*}{ }_{2}<y_{2}$, but $y_{2}{ }^{c}-s_{1} q_{1}>y_{2}{ }^{c}-s^{*}{ }_{1} q_{1}$, since $s^{*}{ }_{1}>s_{1}$, as shown earlier. The total deadweight loss is equal to the sum of individual deadweight losses. In the case of the discrete density function, $f(y)=0$ except for $y \neq y_{L}, y_{M}, y_{H}$ and $y_{2}^{*}=y_{M}$. If $y_{2}{ }^{c}-s_{1} q_{1}>y_{L}>y_{2}{ }^{c}-s^{*}{ }_{1} q_{1}$ the total deadweight losses are equal to $\beta\left(s_{1} q_{1}+y_{M}-y_{2}^{c}\right)\left(q_{2}-q_{1}\right) /\left(1+q_{2}\right)$ and $\alpha\left(s_{1}{ }_{1} q_{1}+y_{L}-y_{2}^{c}\right)\left(q_{2}-q_{1}\right) /\left(1+q_{2}\right)$, respectively, which are not comparable generally. However if $y_{2}{ }^{c}-s^{*}{ }_{1} q_{1}>y_{L}$, the total deadweight losses are equal to $\beta\left(s_{1} q_{1}+y_{M}-y_{2}{ }^{c}\right)\left(q_{2}-q_{1}\right) /\left(1+q_{2}\right)$ and zero, respectively. ${ }^{14}$ It follows that the subsidy reforms in this case would reduce the deadweight loss. However, this may not be the case

\footnotetext{
${ }^{14}$ See Besley and Coate (1991) for another example in which the optimal subsidy implies a zero deadweight loss.
} 


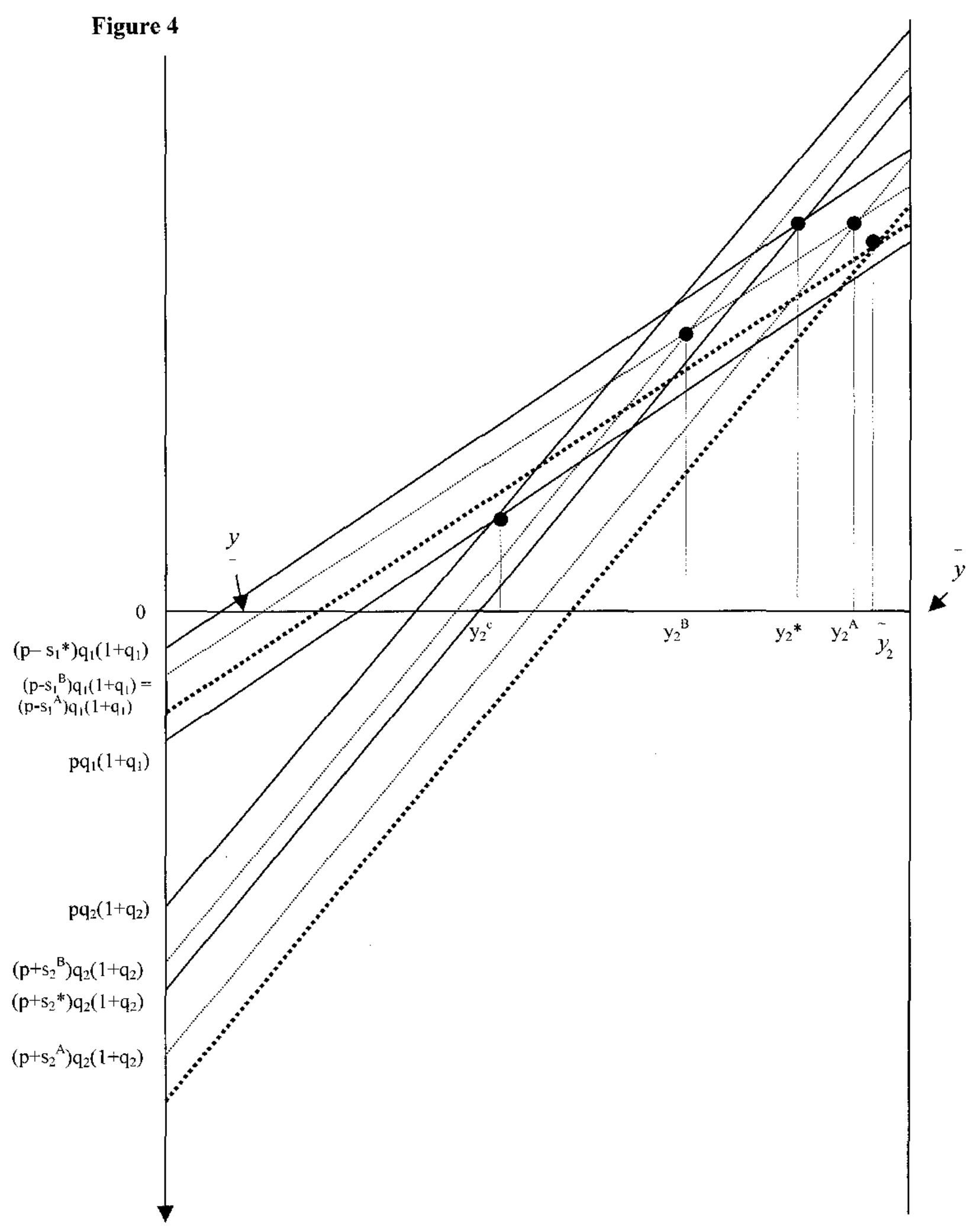




\section{Figure 5}

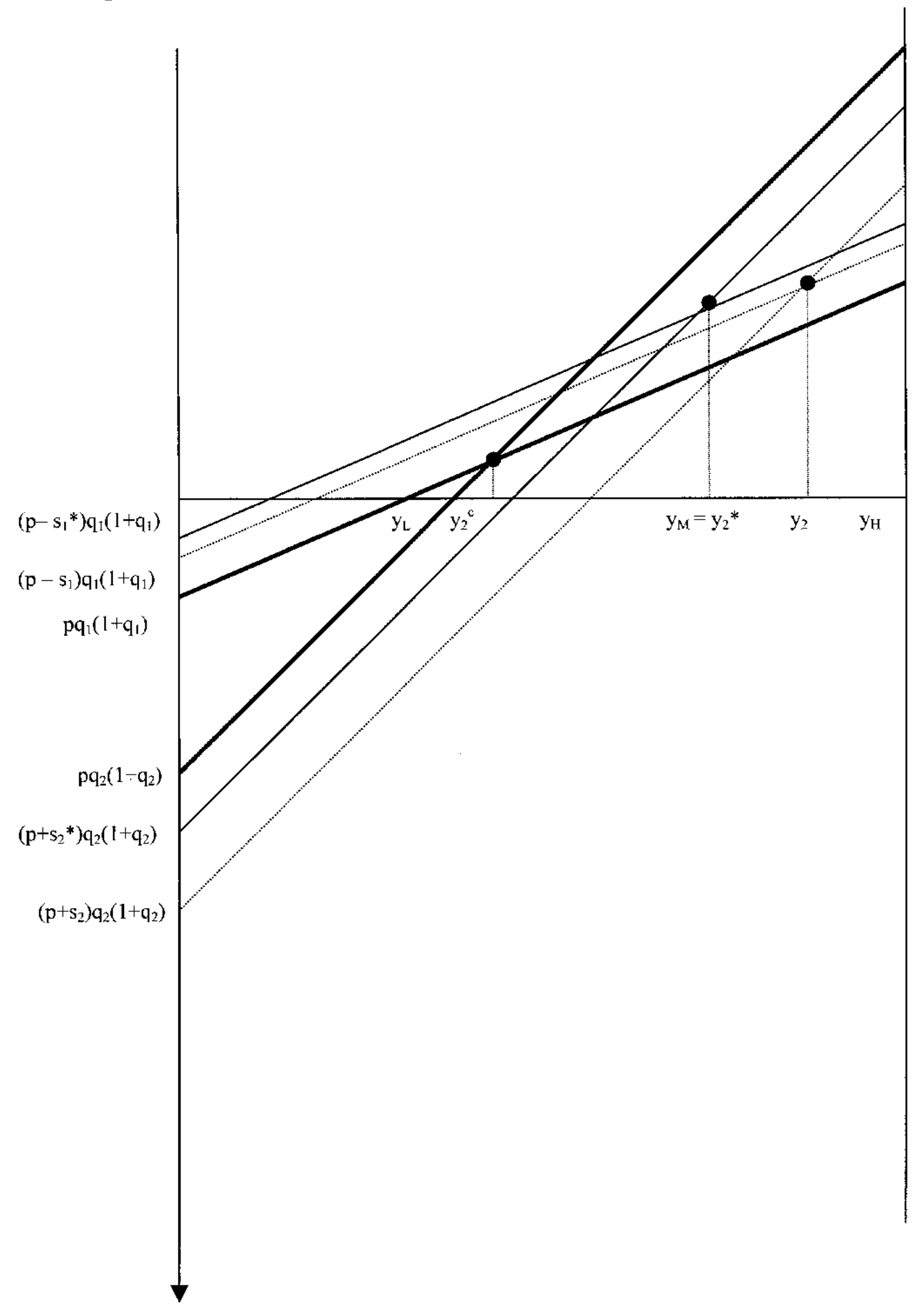


generally. In particular, it may depend on whether $\int_{y^{*}}^{y_{2}} f(y) d y$ is sufficiently large, that is, whether the reforms induce a large enough number of consumers to switch from the subsidized low-quality good to the high-quality one. ${ }^{15}$

\section{Measuring Quality}

In many cases of interest, qualities are given exogenously. For example, the varieties of food grains are determined more or less by nature. In other cases, qualities may be a governmental or an entrepreneurial decision (Mussa and Rosen, 1978; Gabszewicz and Shaked, 1986). For example, health care may be available at a high-quality level in the private sector as well as at a low-quality level in the public sector. In either case, unlike prices and quantities, quality cannot be quantified as such, as it is a representation of the hedonic attributes of goods.

We may point out, however, that the quality of various goods can be deduced from observing a consumer equilibrium.

We can rewrite equations (2) and (3) above as:

$$
y_{1}=\beta_{(1)} p_{(1)}
$$

and

$$
y_{i}=\beta_{(i)} p_{(i)}-\beta_{(i-1)} p_{(i-1)}, i=2, \ldots m
$$

where

$$
\beta_{(1)}=\frac{1+q_{(1)}}{q_{(1)}} \text { and } \beta_{(i)}=\frac{1+q_{(i)}}{q_{(i)}-q_{(i-1)}}, i=2, \ldots m
$$

Data regarding which income groups purchase which goods at what prices can be gathered from consumer and market surveys. Since equations (10) and (11) are linear, the coefficients $\beta_{(i)}$ ' $s$ can be

\footnotetext{
${ }^{15}$ This might be relevant for developing countries where the ongoing economic reforms and globalization have led to a rise in the number and income level of the middle ciass. In such cases, subsidy reforms may reduce not only poverty but also the deadweight loss.
} 
estimated using linear regression methods. Estimates of the various qualities then follow, since by definition

$$
q_{(1)}=\frac{1}{\beta_{(1)}-1} \text {, and } q_{(i)}=1-\frac{\beta_{(i)}}{\beta_{(j-1)}}\left(1+q_{(i-1)}\right), i=2, \ldots m
$$

This clarifies that it is possible to estimate the parameters of our model and do empirical analyses.

\section{Conclusions}

Subsidy reforms for poverty alleviation under budgetary constraints are of considerable interest from a policy point of view. This paper has presented a general framework for characterizing the optimal pattern of subsidies and, therefore, indicated the reforms that may be needed. That there are cases of equilibria in which it may be possible to increase subsidies and at the same time reduce both taxes and the deadweight loss is of great policy significance.

In broad policy terms, the main contribution here is that the prices of the subsidized goods meant for the poor should not be seen in isolation, but in relation to those of nonsubsidized high-quality goods.

Our analysis is applicable to a broad category of issues in developing countries. For instance, in many developing countries insufficient investment in infrastructure, such as health care, education, irrigation systems, public transport, water supply, and municipality services in cities, has seriously undermined economic growth. The main reason (Chander, 1999) behind such low investment is that these services are provided universally at below-market prices. Any attempt to raise these prices is resisted on the grounds that it will have an adverse impact on the poor. Besides the poor, however, the developing countries also have substantial populations of wealthy who would be willing to pay higher prices for better-quality services. Subsidy reforms, along the lines proposed in this paper, can thus induce both public and private investment in these sectors and at the same time improve the fiscal balance. ${ }^{16}$ An example can clarify this point further. Public sector power companies supply electricity to households in Delhi at subsidized rates. There are frequent interruptions in the supply because of insufficient power-generating capacity. Many rich households would be willing to pay higher prices if some power company could ensure uninterrupted (i.e., higher-quality) supply. Allowing private power companies to set up new plants and supply uninterrupted power at market prices to those who are willing would benefit both rich and poor households, as our analysis implies. Besides, it would lead to higher investment in the power sector, which the public sector companies are not able to undertake as, given government's poverty alleviation objective, they cannot raise the price for the power supplied by them.

\footnotetext{
${ }^{16}$ This suggests that link between growth and poverty may not be unidirectional. Progrowth macropolicies may reduce poverty, but policies for poverty alleviation may induce investment and growth.
} 
One possible extension of the model developed in this paper is to treat the case where individual consumers decide on both the quantity of the units they consume and the quality of such units. Intuition suggests that if quantity and quality both enter the utility function, self-targeting and subsidy reforms might both lose some, but not all, of their power. 


\section{References}

Ahmad, Ehtisham, and Luc Leruth, 2000, "Indonesia: Implementing National Policies in a Decentralized Context: Special Purpose Programs to Protect the Poor," IMF Working Paper 00/102 (Washington: International Monetary Fund).

Alderman, Harold, and Kathy Lindert, 1998, "The Potential and Limitations of Self-Targeted Food Subsidies," World Bank Research Observer, Vol. 13 (August), pp. 213-29.

Besley, Timothy, and Stephen Coate, 1991, "Public Provision of Private Goods and the Redistribution of Income," American Economic Review, Vol. 81 (September), pp. 979-84.

Chander, Parkash, 1999, "The Politics of Subsidies in Developing Countries," Reflets et Perspectives de la Vie Economique, Vol. 38, No. 1, pp. 137-38.

Chander, Parkash, and Luc Leruth, 1989, "The Optimal Product Mix for a Monopolist in the Presence of Congestion Effects: A Model and Some Results," International Journal of Industrial Organization. Vol.7, No. 4, pp. 437-49.

Gabszewicz, Jean Jaskold, and Avner Shaked, 1986, "Segmenting the Market: The Monopolist's Optimal Product Mix," Journal of Economic Theory, Vol. 39 (August), pp. 273-89.

Gupta, Sanjeev, and others, 2000, Equity and Efficiency in the Reform of Price Subsidies: A Guide for Policymakers (Washington: International Monetary Fund).

Gupta, Sanjeev, and Walter Mahler, 1995, "Taxation of Petroleum Products: Theory and Empirical Evidence," Energy Economics, Vol. 17 (April), pp. 101-16.

Mussa, Michael and Sherwin Rosen, 1978, "Monopoly and Product Quality," Journal of Economic Theory, Vol. 18 (June), pp. 301-317.

Schwartz, Gerd, and Benedict Clements, 1999, "Government Subsidies," Journal of Economic Surveys, Vol. 13 (April), pp. 119-47.

Tuck, Laura, and Kathy Lindert, 1996,"From Universal Food Subsidies to a Self-Targeted Program: A Case Study in Tunisian Reform," World Bank Discussion Paper No. 351 (Washington: World Bank). 